\title{
PENGARUH HARGA, KUALITAS PELAYANAN, KUALITAS PRODUK DAN LOKASI TERHADAP KEPUASAN PELANGGAN PADA WARUNG MAKAN BAKSO KABUT KABUPATEN JEMBER
}

\author{
Nikinus Kogoya ${ }^{1}$, Andi Muhammad Ismail ${ }^{2}$, Ratih Pispitorini Y.A ${ }^{3}$, Ardhitya Alam Wiguna ${ }^{4}$ \\ Department of Agribusiness Management, Politeknik Negeri Jember 68101 \\ ${ }^{1}$ Nikinuskogoya1212@gmail.com, ${ }^{2}$ andi_m_ismail@polije.ac.id
}

\begin{abstract}
Abstrack
Business developments in the culinary field are followed by increasing competition in the food stall business world, one of which is the Mist Meatball Warung in Jember Regency. Food business managers try to do better in creating new variants in food products, in order to attract customers' attention not to switch to other food stall business competitors. Price, service quality, product quality and location are the determining factors for the level of customer satisfaction. The purpose of this study was to determine the effect of price, service quality, product quality and location, either simultaneously or partially on customer satisfaction at the Meatball Meatball stall. The method in this research is a survey. The population in this study were all customers and the sample of this study was 50 respondents. The results of the research conducted indicate that price and product quality have an effect on customer satisfaction while service quality and location have no significant effect on customer satisfaction. and price is the most dominant variable thus the price offered to customers is competitive. For managers of mist meatball food stalls, it is better to improve the quality of better service, in order to increase customer satisfaction.
\end{abstract}

Keywords: Price, Service, Product, Location, Customer Satisfaction

\begin{abstract}
Abstrak
Perkembangan bisnis di bidang kuliner di ikuti dengan meningkatnya persaingan dunia bisnis warung makan, Salah satuhnya Warung makan bakso kabut di kabupaten Jember. Pengelolah bisnis makanan berusaha lebih baik dalam membuat varianvarian baru dalam produk makanan, agar dapat menarik perhatian pelangan untuk tidak beralih kepada pesaing bisnis warung makan lainnya. Harga, Kualitas pelayanan, kualitas produk dan lokasi merupakan faktor penentu terhadap tingkat kepuasan pelanggan. Tujuan penelitian ini adalah untuk mengetahui pengaruh harga,kualitas pelayanan,kualitas produk dan lokasi, baik secara serempak maupun parsial terhadap kepuasan pelanggan pada warung makan bakso kabut. Metode dalam penelitian ini adalah survei. Populasi dalam penelitian ini adalah seluruh pelanggan dan dan sampel penelitian ini sebanyak 50 responden. Hasil penelitian yang dilakukan menunjukkan bahwa harga dan kualitas produk berpengaruh terhadap kepuasan pelangan sedangkan kualitas pelayanan dan lokasi tidak berpengaruh signifikan terhadap kepuasan pelanggan. dan harga merupakan variabel yang paling dominan dengan demikian harga yang ditawarkan kepada pelangan kompetitif. Bagi para pengelola warung-warung makan bakso kabut, sebaiknya meningkatkan kualitas pelayanan yang lebih baik, agar dapat meningkatkan kepuasan pelanggan.
\end{abstract}

Kata kunci: harga, pelayanan, produk, lokasi, kepuasan pelanggan.

\section{Pendahuluan}

Perkembangan bisnis di bidang kuliner ini diikuti dengan meningkatnya persaingan dunia bisnis rumah makan. Hal ini yang menjadi ancaman dan tantangan bagi beberapa warung makan karena persaingan yang semakin ketat. Persaingan yang semakin ketat akan menjadi suatu tantangan bagi pelaku bisnis agar dapat menarik perhatian konsumen untuk tidak beralih kepada pesaing bisnis rumah makan lainnya. Pelaku usaha dituntut agar dapat mempertahankan pasar dan merebut pasar pesaing yang sudah ada dengan cara memberikan kepuasan serta mampu memenuhi kebutuhan dan keinginan konsumen yang terus berubah-ubah. Salah satu rumah makan yang menjaga kepuasan pelanggan adalah warung makan Bakso Kabut.

Warung makan Bakso Kabut merupakan salah satu bisnis usaha Bakso yang banyak di minati oleh berbagai kalangan yang berada di Kabupaten Jember. Seiring perkembangan saat ini banyak warung makan 
di Kabupaten Jember yang menyajikan produk sejenis yaitu makanan berupa olahan berbahan baku daging sapi dan telur. Salah satu upaya yang harus dilakukan oleh pemilik warung makan yaitu bagaimana untuk tetap mempertahankan dan meningkatkan jumlah pelanggannya. Hal ini yang menjadi tantangan bagi pelaku bisnis untuk selalu berinovasi memberikan kepuasan pelanggan.Penelitian ini bertujuan Untuk menguji dan menganalisis pengaruh harga, kualitas pelayanan, kualitas produk dan lokasi terhadap kepuasan pelanggan secara serempak maupun parsial pada warung makan Bakso Kabut di Kabupaten Jember.

\section{Metode Penelitian}

\subsection{Jenis Penelitian}

Jenis penelitian yang di gunakan oleh peneliti dalam penelitian ini adalah penelitian kuantitatif untuk menganalisis pengaruh harga,kualitas pelayanan,kualitas produk dan lokasi terhadap kepuasan pelanggan warung makan bakso kabut di kabupaten jember.

\subsection{Waktu dan tempat penelitian}

Penelitian ini akan dilaksanakan di jalan Rasmalan, Krajan, Kemuning Lor,Kecamatan Arjasa, Kabupaten Jember. Lebih tepatnya di warung makan baksokabut Jember. Jangka waktupelaksanaan penelitian ini adalah selama \pm 6 bulan. Waktu tersebut digunakan dari tahap awal sebelum penelitian sampai denganpenyelesaian penelitian yaitu awal bulan september 2020 sampai dengan 25 februari 2021.

\subsection{Instrumen Penelitian}

Metode yang di gunakan dalam pengambilan data yaitu:
a. Observasi
b. Kuisioner
c. Wawancara

\subsection{Teknik Pengambilan Sampel}

Teknik pengambilan sampel yang digunakan dalam penelitian ini adalah sampling Insidental. Menurut Sugiyono (2014:85),Sampling Insidental merupakan teknik penentuan sampel berdasarkan kebetulan, yaitu siapa saja yang secara kebetulan atau insidental bertemu dengan peneliti dapat digunakan sebagai sampel, biladipandang orang yang kebetulan ditemui itu cocok sebagai sumber data

\subsection{Metode Analisis}

\section{a. Uji Validitas}

Uji validitas digunakan untuk mengukur sah atau valid tidaknya suatu kuisioner. Suatu kuisioner dikatakan valid jika pertanyaan pada kuisioner mampu untuk mengungkapkan sesuatu yang akan diukur oleh kuisioner tersebut Menurut Sugiyono (1999:115) dalam Sherly (2019:22) bahwa dapat diketahui dengan cara mengkorelasikan antara skor butir dengan skor total bila korelasi $r$ di atas 0,30 maka dapat disimbulkan bahwa instrumen tersebut valid sebaliknya bila korelasi $\mathrm{r}$ di bawah 0,30 maka dapat disimbulkan bahwa butir instrumen tersebut tidak valid sehingga harus diperbaiki atau dibuang.

\section{b. Uji Reliabilitas}

Uji reliabilitas adalah alat yang di pakai untuk menunjukkan sejauh mana suatu hasil pengukuran relatif konsisten apabila alatukur tersebut digunakan berulang kali Menurut Ghozali (2006:45) reliabilitas sebenarnya adalah alat untukmengukur suatu kuesioner yang merupakan indikator dari variabel atau konstruk.Suatu kuisioner dikatakan reliabel atau handal jika jawaban seseorang terhadappernyataan adalah konsisten atau stabil dari waktu ke waktu. Apabila variabel yang diteliti mempunyai cronbach's alpha $(\alpha)>60 \%(0,60)$ maka variabel tersebut dikatakan reliabel, sebaliknya cronbach's alpha $(\alpha)<$ $60 \%(0,60)$ makka variabel tersebut dikatakan tidak reliable.

\subsection{Analisis Regresi Linier Berganda}

Analisis regresi berganda digunakan oleh peneliti,bila peneliti bermaksud meramalkan bagaimana keadaan (naik turunnya) variabel dependen, bila dua atau lebih variabel independen sebagai faktor predictor di manipulasi (di naik turunkan nilainya) Sugiyono (2014:275. Jadi analisis regresi berganda akandilakukan bila jumlah variabel independennya minimal dua. Persamaan regresiuntuk empat prediktor adalah.

$\mathrm{Y}=\mathrm{a}+\mathrm{b}_{1} \mathrm{X}_{1}+\mathrm{b}_{2} \mathrm{X}_{2}+\mathrm{b}_{3} \mathrm{X}_{3}+\mathrm{b} 4 \mathrm{x} 4+\mathrm{bnXn}+\mathrm{e}$ .... (1)

Keteranan :

$\mathrm{Y}=$ Kepuasan Pelanggan

$\mathrm{a}=$ Konstanta

$\mathrm{b}=$ Koefisien dari variabelindependen $(\mathrm{X}) \mathrm{X} 1=$ Lokasi

X2= Harga X3=Kualitas Pelayanan X4= Lokasi

$\mathrm{e}=$ standard error Koefisien Determinasi (R2)

Analisis ini di gunakan untuk menunjukkan besar sumbangan dari variabel penjelas terhadap variabel respon Sugiarto (2006:259).

\subsection{Uji F}

Uji f korelasi ganda merupakan angka yang menunjukkan arah dan kuatnya antara dua variabel independen secara bersama-sama atau lebih dengan satu variabel dependen Sugiyono (2014:231). Apabilah Fhitung $\geq$ Ftabel, pada taraf signifikan yang ditentukan maka Ho diterima dan Ha ditolak sehingga ada pengaruh positif dan signifikan variabel bebas terhadap variabel terikat. Apabila Fhitung $\leq$ Ftabel, pada taraf signifikan yang ditentukan maka Ho ditolak 
dan Ha diterima sehingga tidak ada pengaruh positif dan signifikan variabel bebas terhadap variabel terikat.

\subsection{Uji t}

Digunakan untuk menganalisis bila bermaksud ingin mengetahui pengaruh atau mengetahui hubungan antara variabel independen dan dependen, dimana salah satu variabel independennya dibuat tetap/dikendalikan (Sugiyono, 2014:235). Thitung $\geq$ ttabel, artinya variabel bebas secara parsial berpengaruh signifikan dengan derajat keyakinan digunakan sebesar $\alpha=5 \%$. thitung $\leq$ ttabel, artinya variabel bebas secara parsial tidak berpengaruh secara signifikan dengan keyakinan yang digunakan sebesar $\alpha$ $=5$

\section{Hasil dan Pembahasan}

\subsection{Hasil}

a. Frekuensi Usia, jenis kelamin dan pekerjaan responden

Tabel 1 menunjukkan bahwa pelangganpada warung makan Bakso Kabut Jember yang dijadikan responden adalah sebanyak 50 responden,dengan rentang usia antara 17-23 tahun sebanyak 34 responden, rentang usia 24-30 tahun sebanyak 15 responden, rentang usia 45-50 tahun sebanyak 1 responden.Responden berjenis kelamin pria sebanyak 24 responden dan berjenis kelaminwanita sebanyak 26 responden. Berjenis kelamin pria yang memiliki pekerjaansebagai mahasiswa sebanyak 7 responden, yang bekerja sebagai Pegawai NegeriSipil (PNS) sebanyak 2 responden, yang bekerja sebagai wiraswasta sebanyak 11responden, dan yang bekerja sebagai lain-lain sebanyak 2 responden. Berjeniskelamin wanita yang memiliki pekerjaan sebagai mahasiswa sebanyak 11responden, yang bekerja sebagai Pegawai Negeri Sipil (PNS) sebanyak 1responden, yang bekerja sebagai wiraswasta sebanyak 5 responden, yang bekerjasebagai ibu rumah tangga (IRT) sebanyak 2 responden dan yang bekerja sebagailain-lain sebanyak 8 responden.

Tabel 1. Frekuensi Usia, jenis kelamin dan pekerjaan responden

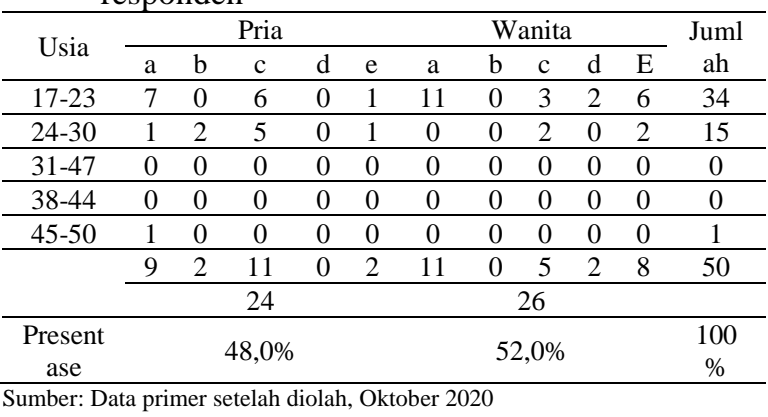

b. Uji Validitas

Tabel 2. hasil Uji Validitas

\begin{tabular}{ccccc}
\hline Variabel & Item & r-Hitung & r-Tabel & Ket. \\
\hline
\end{tabular}

\begin{tabular}{|c|c|c|c|c|}
\hline \multicolumn{5}{|c|}{ Pertanyaan } \\
\hline \multirow{4}{*}{$\begin{array}{l}\text { Harga } \\
\text { (X1) }\end{array}$} & $\mathrm{X} 1.1$ & 0.665 & 0.2787 & Valid \\
\hline & $\mathrm{X} 1.2$ & 0.743 & 0.2787 & Valid \\
\hline & $\mathrm{X} 1.3$ & 0.551 & 0.2787 & Valid \\
\hline & $\mathrm{X} 1.4$ & 0.559 & 0.2787 & Valid \\
\hline \multirow{4}{*}{$\begin{array}{c}\text { Kualitas } \\
\text { Pelayana } \\
\text { n (X2) }\end{array}$} & $\mathrm{X} 2.1$ & 0.777 & 0.2787 & Valid \\
\hline & $\mathrm{X} 2.2$ & 0.704 & 0.2787 & Valid \\
\hline & $\mathrm{X} 2.3$ & 0.784 & 0.2787 & Valid \\
\hline & $\mathrm{X} 2.4$ & 0.817 & 0.2787 & Valid \\
\hline \multirow{4}{*}{$\begin{array}{c}\text { Kualitas } \\
\text { Produk } \\
\text { (X3) }\end{array}$} & $\mathrm{X} 3.1$ & 0.801 & 0.2787 & Valid \\
\hline & $\mathrm{X} 3.2$ & 0.597 & 0.2787 & Valid \\
\hline & X3.3 & 0.844 & 0.2787 & Valid \\
\hline & X3.4 & 0.718 & 0.2787 & Valid \\
\hline \multirow{4}{*}{$\begin{array}{c}\text { Lokasi } \\
\text { (X4) }\end{array}$} & $\mathrm{X} 4.1$ & 0.766 & 0.2787 & Valid \\
\hline & $\mathrm{X} 4.2$ & 0.665 & 0.2787 & Valid \\
\hline & $\mathrm{X} 4.3$ & 0.756 & 0.2787 & Valid \\
\hline & $\mathrm{X} 4.4$ & 0.711 & 0.2787 & Valid \\
\hline \multirow{4}{*}{$\begin{array}{c}\text { Kepuasan } \\
\text { Pelangga } \\
\mathrm{n}(\mathrm{Y})\end{array}$} & $\mathrm{Y} 1$ & 0.588 & 0.2787 & Valid \\
\hline & $\mathrm{Y} 2$ & 0.662 & 0.2787 & Valid \\
\hline & Y3 & 0.623 & 0.2787 & Valid \\
\hline & Y4 & 0.756 & 0.2787 & Valid \\
\hline
\end{tabular}

Tabel 2 menunjukkan bahwa nilai $r$ Tabel sebesar 0.2787, sehingga dapat disimpulkan bahwa semua instrumen pada variabel memiliki hasil nilai r-hitung > r-tabel. Berdasarkan perhitungan tersebut, maka itemitem pertanyaan pada kuesioner penelitian tersebut dinyatakan valid, sehingga item pertanyaan tersebut layak untuk digunakan sebagai alat dalam pengumpulan data.

c. Uji Realibilitas

Tabel 3. Hasil Uji Reliabilitas

\begin{tabular}{llll}
\hline $\begin{array}{l}\text { Cronbach,s } \\
\text { Alpha }\end{array}$ & Batas Penerimaan & Item & Keterangan \\
\hline 0,888 & 0,883 & 20 & Reliabel \\
\hline
\end{tabular}

Sumber: Data primer setelah diolah, Oktober 2020

Tabel 3 terlihat bahwa nilai Cronbach,s Alpha, sebesar 0.888 lebih besar dari nilai kritis reliabilitas sebesar 0,60 sehingga dapat disimpulkan bahwa reliabilitas instrumen dapat dipercaya atau dapat dikatakan hasil instrumen tersebut bersifat reliabel dan konsisten walaupun digunakan berkali-kali pada waktu yang berbeda.

d. Uji Linier Berganda

$Y=-0,072+0,561 X_{1}-0,017 X_{2}+0,284 X_{3}+0,178 X 4+e$

1. Nilai Konstanta sebesar - 0,072

Nilai konstanta bernilai negatif. Artinya ketika keempat variabel diabaikan maka variabel kepuasan pelanggan bernilai negatif sebesar $-0,072$.

2. Nilai Koefisien harga (X1) sebesar 0.561

Nilai koefisien regresi untuk harga bernilai positif. Artinya kepuasan pelanggan pada warung makan Bakso Kabut akan meningkat sebesar 0.561 satuan, dengan asumsi bahwa nilai variabel lainnya tetap.

3. Nilai koefisien kualitas pelayanan (X2) sebesar - 
0.017

Nilai koefisien kualitas pelayanan (X1) bernilai negatif sebesar $-0,017$ artinya jika variabel bebas lainnya bernilai tetap atau bernilai nol dan variabel kualitas pelayanan (X1) mengalami kenaikan 1 satuan, maka kepuasan pelanggan (Y) akan mengalami penurunan sebesar 0,017. Nilai koefisien bernilai negatif artinya terjadi hubungan negatif antara variabel kualitas pelayanan terhadap kepuasan pelanggan (Y), semakin naik nilai variabel kualitas pelayanan maka kepuasan pelanggan akan menurun.

4. Nilai Koefisien kualitas produk (X3) sebesar 0.284 Nilai koefisien kualitas produk (X3) bernilai positif sebesar 0,284. Hal ini menujukkan bahwa kepuasan pelanggan pada warung makan Bakso Kabut akan meningkat sebesar 0.284 satuan, dengan asumsi bahwa nilai variabel lainnya tetap.

5. Nilai Koefisien lokasi (X4) sebesar 0,178

Nilai koefisien lokasi (X4) bernilai positif sebesar 0,178. Hal ini menujukkan bahwa kepuasan pelanggan pada warung makan Bakso Kabut akan meningkat sebesar 0.178 satuan, dengan asumsi bahwa nilai variabel lainnya tetap.

Hasil Analisis Koefisiensi Korelasi Determinasi (Adjustd R2) dapat diketahui bahwa nilai koefisien determinasi Adjusted $R$ Square sebesar 0,465, hal ini berarti kemampuan variabel bebas dalam menjelaskan variabel terikat adalah sebesar $46,5 \%$ sisanya $53,5 \%$ dijelaskan oleh variabel lain yang tidak bahas dalam penelitian ini.

Tabel 4. Hasil Analisis Koefisiensi Korelasi Determinasi (Adjustd R2)

\begin{tabular}{ccccc}
\hline \multicolumn{5}{c}{ Model Summary } \\
\hline Model & R Square & $\begin{array}{c}\text { Adjusted R } \\
\text { Square }\end{array}$ & $\begin{array}{c}\text { Std. Error of the } \\
\text { Estimate }\end{array}$ \\
\hline $\mathbf{1}$ & $713^{\text {a }}$ &, 509 &, 465 & 1,307 \\
\hline
\end{tabular}

a.Predictors: (Constant), LOKASI X4, HARGA X1, KUALITAS PRODUK X3, KUALITAS PELAYANAN X2

Sumber: Data primer setelah diolah, Oktober 2020

e. Uji F

Tabel 5. Hasil Analsis Uji F

\begin{tabular}{lccccc}
\hline \multicolumn{5}{c}{ ANOVA } \\
\hline Model & $\begin{array}{c}\text { Sum of } \\
\text { Square }\end{array}$ & $\mathrm{f}$ & $\begin{array}{c}\text { Mean } \\
\text { Square }\end{array}$ & F & Sig. \\
\hline Regression & 79,608 & \multicolumn{1}{c}{19,902} & 11,647 &, $000^{\text {ab }}$ \\
\hline Residual & 76,892 & 5 & 1,709 & & \\
\hline Total & 156,500 & 9 & & \\
\hline a. Dependent Variabel: KEPUASAN PELANGAN (Y) & \\
\hline b. Predictors: & (Constant), LOKASI & X4, HARGA & X1, \\
KUALITAS PRODUK X3, KUALITAS PELAYANAN X2
\end{tabular}

Pada Tabel 5 hasil dari analisis regresi diperoleh nilai
F hitung sebesar 11,647 dan nilai signifikan sebesar 0,000 yang menunjukkan bahwa nilai $\mathrm{F}$ hitung > nilai F tabel sebesar 2.57 maka hipotesis 1 diterima, yang berarti bahwa variabel harga (X1), kualitas pelayanan (X2), kualitas produk (X3) dan lokasi secara serempak berpengaruh terhadap kepuasan pelanggan (Y).

f. Uji t

Tabel 6. Hasil Analisis Uji t

\begin{tabular}{|c|c|c|c|c|c|}
\hline \multicolumn{6}{|c|}{ Coefficients* } \\
\hline \multirow[b]{2}{*}{ Model } & \multicolumn{2}{|c|}{$\begin{array}{l}\text { Unstandardized } \\
\text { Coefficients }\end{array}$} & \multicolumn{2}{|c|}{$\begin{array}{l}\text { Unstandardized } \\
\text { Coefficients }\end{array}$} & \multirow[b]{2}{*}{ Sig. } \\
\hline & & $\begin{array}{l}\text { Std. } \\
\text { Error }\end{array}$ & & Beta & \\
\hline (Constant) &,- 072 & 2,636 & &,- 027 & 978 \\
\hline HARGA (X1) &, 561 &, 173 & ,408 & 3,241 & $002^{\mathrm{a}}$ \\
\hline $\begin{array}{l}\text { KUALITAS } \\
\text { PELAYANAN } \\
(\mathrm{X} 2)\end{array}$ &,- 017 & , 141 &,- 017 &,- 122 & 903 \\
\hline $\begin{array}{l}\text { KUALITAS } \\
\text { PRODUK (X3) }\end{array}$ & ,284 & ,138 & ,271 & 2,054 & 046 \\
\hline LOKASI (X4) & ,178 & ,133 & ,200 & ,337 & 188 \\
\hline
\end{tabular}

a. Dependent Variable: KEPUASAN PELANGGAN (Y)

Sumber: Data primer setelah diolah, Oktober 2020

Tabel 6 menjelaskan bahwa variabel harga (X1) merupakan variabel yang berpengaruh paling dominan terhadap kepuasan pelanggan pada Warung makan bakso Kabut Kabupaten Jember

\subsection{Pembahasan}

a. Pengaruh Secara Serempak Variabel Bebas (X) Terhadap Variabel Terikat (Y)

secara bersama-sama dalam hasil analisis dari uji $\mathrm{F}$ dapat dilihat bahwa variabel harga (X1), kualitas pelayanan (X2), kualitas produk (X3) dan lokasi berpengaruh signifikan terhadap variabel kepuasan pelanggan (Y) pada warung makan Bakso Kabut Jember. Hal tersebut dapat ditunjukkan dari nilai Fhitung mempunyai nilai sebesar 11,647> Ftabel 2.57 dengan taraf signifikan yaitu $5 \%$ atau 0.05 .

Maka hasil penelitian ini konsisten dengan penelitian terdahulu yang dilakukan oleh Afandi (2017) yang meneliti tentangPengaruh Lokasi, Harga dan Kualitas Pelayanan Terhadap Kepuasan Pelanggan Di Mister Te Tawang Mangu Jember.

\section{b. Pengaruh Secara Parsial Faktor Harga (X1)} Terhadap KepuasanPelanggan (Y)

Secara terpisah dari hasil analisis uji t dapat dilihat bahwa variabel bebas harga (X1), mempunyai nilai $\mathrm{t}$ hitung sebesar 3, 241. Dan nilai t tabel 2.011. Nilai tersebut menunjukkan bahwa thitung lebih besar dari nilai t tabel, sehingga variabel harga (X1) berpengaruh signifikan terhadap variabel kepuasan pelanggan (Y). Maka hasil dari penelitian ini konsisten dengan penelitian terdahulu yang dilakukan oleh Puri (2016) 
Afandi (2017), Situmeang (2017), Rizal (2017), Adi (2012), yang mengemukakan bahwa faktor harga, berpengaruh secara signifikan pada uji parsial terhadap kepuasan pelanggan (Y).

\section{c. Pengaruh Secara Parsial Faktor Kualitas Pelayanan (X2) Terhadap Kepuasan Pelanggan (Y)}

Secara terpisah dari hasil analisis uji t dapat dilihat bahwa variabel kualitas pelayanan (X3), mempunyai nilai t hitung sebesar 0,122 dan nilai t tabel 2.011 . Nilai tersebut menunjukkan bahwa t hitung lebih kecil dari nilai t tabel, sehingga variabel kualitas pelayanan (X3) berpengaruh tidak signifikan terhadap variabel kepuasan pelanggan $(\mathrm{Y})$.

Maka hasil dari penelitian ini konsisten dengan penelitian terdahulu yang dilakukan oleh Sherly (2020) yang mengemukakan bahwa faktor kualitas pelayanan, berpengaruh tidak signifikan pada uji parsial terhadap kepuasan pelanggan $(Y)$.

\section{d. Pengaruh Secara Parsial Faktor Kualitas Produk} (X3) Terhadap Kepuasan Pelanggan (Y)

Secara terpisah dari hasil analisis uji t dapat dilihat bahwa variabel kualitas produk (X3), mempunyai nilai t hitung sebesar 2,054 dan nilai t tabel 2.011. Nilai tersebut menunjukkan bahwa t hitung lebih besar dari nilai ttabel, sehingga variabel kualitas produk (X3) berpengaruh signifikan terhadap variabel kepuasan pelanggan $(\mathrm{Y})$.

Maka hasil dari penelitian ini konsisten dengan penelitian dari penelitian terdahulu yang dilakukan oleh Puri (2016) yang mengemukakan bahwa faktor kualitas produk, berpengaruh secara signifikan pada uji parsial terhadap kepuasan pelanggan (Y).

e. Pengaruh Secara Parsial Faktor Lokasi (X4) Terhadap KepuasanPelanggan (Y)

Secara terpisah dari hasil analisis uji t dapat dilihat bahwa variabel lokasi (X1) mempunyai nilai t hitung sebesar 1,337 dan nilai $t$ tabel 2.011. Nilai tersebut menunjukkan bahwa $\mathrm{t}$ hitung lebih kecil dari nilai $\mathrm{t}$ tabel, sehingga variabel lokasi (X1) berpengaruh tidak signifikan terhadap variabel kepuasan pelanggan (Y). Maka hasil dari penelitian ini konsisten dengan penelitian terdahulu yang dilakukan oleh Situmeang (2017), yang meneliti tentang adanya pengaruh parsial lokasi terhadap Kepuasan Konsumen.Artinya variabel lokasi tidak menjadi faktor utama dalam memberi kepuasan pelanggan pada warung makan Bakso Kabut Jember, melainkan ada faktor lain yang menjadi faktor utama atau tolak ukur dalam memenuhi kepuasan pelanggan seperti adanya: kuantitas porsi kesesuaian harga dengan manfaat produk, pemberian diskon harga, dan atau adanya penawaran khusus pada produk maupun layanan

\section{Penutup}

Hasil penelitian yang dilaksanakan pada warung makan Bakso Kabut Jember dapat disimpulkan sebagai berikut :

a. Pengujian regresi secara serempak atau bersamasama diperoleh kesimpulan bahwa variabel harga (X1), kualitas pelayanan (X2), kualitas produk (X3) dan lokasi (X4) berpengaruh signifikan terhadap kepuasan pelanggan (Y) pada warung makan Bakso Kabut Jember.

b. Pengujian regresi secara parsial diperoleh kesimpulan sebagai berikut :

1. Variabel harga (X1) berpengaruh signifikan terhadap kepuasan pelanggan (Y) pada warung makan Bakso Kabut Jember.

2. Variabel kualitas pelayanan (X2)berpengaruh tidak signifikan terhadap kepuasan pelanggan(Y) pada warung makan Bakso Kabut Jember.

3. Variabel kualitas produk (X3) berpengaruh signifikan terhadap kepuasan pelanggan (Y) pada warung makan Bakso Kabut Jember.

4. Variabel lokasi (X4) berpengaruh tidak signifikan terhadap kepuasan pelanggan (Y) pada warung makan Bakso Kabut Jember.

c. Variabel yang paling dominan dalam mempengaruhi kepuasan pelanggan (Y) pada warung makan Bakso Kabut adalah variabel harga (X1).

\section{Daftar Pustaka}

1. Bates, R. Dan Khasawneh, S. 2005 Organizational Learning Culture, Learning Transfer Climate, And Perceived Innovation In Jordanian Organization International Journal Of Training And Development, 9 (2), 96- 109.

2. Essinger, F. Dan Wylie. Pengaruh Produk, Kualitas Pelayanan, Dan Lokasi Terhadap Kepuasan Pelanggan (Studi Kasus Pada Baks Lapangan Tembak).Universitas Diponegoro: Semarang.

3. Gaspersz, V. 2002. Total Quality Management. Jakarta : Pt.Gramedia Pustaku Tama.

4. Ghozali, I. 2006. Aplikasi Analisis Multivariate Dengan Program Spss.Semarang Badan Penerbit Universitas Diponegoro.

5. Guntur, Dr. Effendi M. 2010. Transformasi Manajemen Pemasaran + Memangun Citra Negara. Sagung Seto,Jakarta.

6. Hardiyanti, P. 2017. Pengaruh Kualitas Pelayanan Terhadap Kepuasan Pelangan Pada Rumah Makan Takana Juo Di Makassar.

7. Idris, A. 2017. Pengaruh Lokasi, Harga Dan Kualitas Pelayanan Terhadap Kepuasan Pelanggan Di Mister Te Tawang Mangu Jember.

8. Kasmir Dan Jakfar 2003. Studi Kelayakan Bisnis Edisi Revisi. Jakarta:Prenadamedia 
Group.

9. Kotler, P. 2012. Manajemen Pemasaran.Analisis.Perencanaan. Implementasi Dan Pengendalian. Edisi Ke-2. Jakarta :Erlangga.

10. Lina, S. S. 2017. Pengaruh Kualitas Pelayanan, Harga Dan Lokasi Terhadap Keuasan Konsumen Pada Rumah Makan Istana Hot Plate Medan.

11. Lupiyoadi, R. Manajemen Pemasaran Jasa, Teori Dan Praktek. Jakarta: Salemba Empat, 200.

12. Melya,P.2016. Pengaruh Kualitas Produk, Harga, Dan Kualitas Pelayananterhadap Kepuasan Konsumen Pada Rumah Makan Provita Bandar Lampung.

13. Muhamad, A. R.2017. Pengaruh Kualitas Pelayanan Dan Harga Terhadap Kepuasan Pelanggan Pada Bakso H.Yatmin Bekasi Timur.

14. Margenta Dan Edwin. 2012.Pengaruh Kualitas Makanan, Harga Dan Lokasi Terhadap Kepuasan Konsumen Martabak Kirana Di Kabupaten Slema (Studi Kasus Pada Ukm
Martabak Kirana). Universitas Pgri: Yogyakarta. 15. Sumarni, 2000. Ekonomi Ketenaga Kerjaan, Edisi Terjemahan Teori Yogyakarta.

16. Sopiah Dan Syihabudhin. 2008.Manajemen Bisnis Ritel. Yogyakarta: Andi Yogyakarta.

17. Sugiyono. 2014.Metode Penelitian Kuantitatif, Kualitatif, Dan R\&D. Bandung:Al Abeta.

18. Santoso, S. 2014. Statistik Parametrik Konsep Dan Aplikasi Dengan Spss. Jakarta: Pt.Elek Medis Komputindo.

19. Tjiptono, F. 2008. Strategi Pemasaran. Yogyakarta: Andi

20. Sherly (2019) Melakukan Penelitian Yang berjudul"Pengaruh Kualitas Pelayanan, Kualitas Produk Dan Lokasi Terhadap Kepuasan Pelanggan (Studi Kasus Pada Rumah Makan Ayam Gephok Pak Giek Di Kecamatan Sumbersari Kabupaten Jember".

21. Umar, H. 2002.Metode Riset Bisnis Dilengkapi Contoh, Proposal, Dan Hasil Riset Bidang Manajemen Dan Akuntasi. Jakarta: Pt Gramedia Pustaka Utama 